\title{
Happiness Donut: A Confucian Critique of Positive Psychology*
}

\author{
Louise Sundararajan
}

\begin{abstract}
An empirically based version of the good life as proposed by positive psychology is a donut with something missing at the core - the moral map. This paper addresses ramifications of this lacuna, and suggests ways to narrow the gap between science and life. By applying an extended version of the self-regulation theory of Higgins to a cross cultural analysis of the good life as envisioned by Seligman and Confucius, respectively, this paper sheds light on the culturally encapsulated value judgments behind positive psychology, examines issues at stake in an empirically based version of the good life, and suggests, for future research, alternative approaches that may better fulfill the promises of positive psychology.
\end{abstract}

Happiness Donut: A Confucian Critique of Positive PSYCHOLOGY

Positive psychology has two versions, strong and weak. The weak version claims that we can benefit from studying the so far neglected "positive" attributes of life. Except for its overly simplistic polarization of the positive and the negative (see Solomon \& Stone, 2002), this claim is rather innocuous. But at the same time it cannot be taken seriously as an innovation in science. If the whole thing is a matter of shuffling research agendas, then the pendulum is bound to swing back to the negative, when in the foreseeable future the positive side of the coin has generated silos of data. The strong version of positive psychology is more interesting, as it goes beyond another round of the pendulum.

The strong version of positive psychology is best expressed by Seligman and Csikszentmihalyi in their definitive statement of the movement (2000), in which they urged "social and behavioral sciences" to "articulate a vision of the good life that is empirically sound" (p. 5). This claim is bold and innovative, but problematic. To the extent that

* Thanks are due James R. Averill for his helpful comments on an earlier draft of this paper. 
the problems inherent in the strong version of positive psychology are emblematic of psychology as a science, a critique of positive psychology will be worthwhile. Aiming at the wider implications for psychology in general, this paper does not intend to provide an exhaustive literature review, but will give instead a general outline of issues at stake in the positive psychology's vision of the good life.

What is the good life? In his book Authentic Happiness (2002), Seligman answers this question by postulating three flavors of happiness - the pleasant life, characterized by positive emotions; the good life, characterized by gratification from the practice of one's "signature strength"; and the meaningful life, characterized by serving goals and purposes that transcend those of the individual self. He is emphatic about the fact that his model implies no hierarchies: "It does not . . . as a theory, value any one of these lives above the others" (p. 303, note 249). It is along the same line of scientific "neutrality" that Seligman poses the following question:

Imagine a sadomasochist who comes to savor serial killing and derives great pleasure from it. Imagine a hit man who derives enormous gratification from stalking and slaying. Imagine a terrorist who, attached to al-Qaeda, flies a hijacked plane into the World Trade Center. Can these three people be said to have achieved the pleasant life, the good life, and the meaningful life, respectively? (p. 303, note 249)

And he answers his own question in the affirmative: "The answer is yes. I condemn their actions, of course, but on grounds independent of the theory in this book" (p. 303, note 249).

By excising the value question for the sake of "scientific neutrality," Seligman has given us a model of the good life devoid of a moral map. This seriously undermines the credibility of his model, for it is questionable whether any form of life that is considered "good"- the "good life" broadly defined to include all three versions of happinesscan be devoid of a moral map. The problem with the neutrality claim does not stop here, however. There is an inherent contradiction in Seligman's version of the good life: it fails to articulate a moral map on the one hand; and it is not free from value judgments, on the other. Anchored in but not confined to the Confucian tradition, my critique consists of three parts: Part I examines the nature of moral maps, and shows how the neutrality claim is tantamount to a failure on the part of the scientists to make explicit their own value assumptions; part II gives close reading of a text that is paradigmatic of the strong version of positive psychology-Seligman's book Authentic Happiness. My analysis of this book consists of two strategies: a. citing counter examples from Confucian texts, primarily the Analects, to show an alternative vision of the good life; and b. using psychological theories and 
research to shed light on the implicit value judgments behind the good life as envisioned by Seligman and Confucius respectively. Implications of this analysis will be discussed in part three, the concluding section.

\section{What's missing at the core?}

Questions concerning the quality of life, and the kind of beings we are or want to be are intimately related. That is why questions of the good life are usually couched in terms of what it means to be human. Consider an influential pronouncement about human nature by the Confucian philosopher Mencius:

One is not a human without the feeling of sympathy. One is not a human without the feeling of shame. One is not a human without the feeling of reverence. One is not a human without the feeling of approval [and disapproval of right and wrong]. (Mengzi, cited in Liu, 2002, p. 101)

The above statement of Mencius is a good example of what Taylor (1985) refers to as "strong evaluation" Implicit in the strong evaluation is the drawing of a moral map, which "involves defining what it is we really are about, what is really important to us; it involves entering the problematic area of our self-understanding and self-interpretation" (p. 68). As such the moral map consists of "certain essential evaluations which provide the horizon or foundation for the other evaluations one makes" (p. 39), such as happiness or the good life. Elsewhere, Taylor (1997) refers to the moral map as the "horizon" of significance, or "a background of intelligibility" (p. 37). It is through this horizon of significance that the self gains its context and identity, as he points out: "The agent seeking significance in life, trying to define him- or herself meaningfully, has to exist in a horizon of important questions" (p. 40).

As the horizon of significance, the moral map adds another dimension to our desires. For instance, in courage "we are moved by something higher than mere impulse or the mere desire to live" (Taylor, 1985 , p. 25, note 8). Taylor (1985) goes on to say that "If someone for instance thought that there was nothing higher than life and the avoidance of pain ... he would have no place in his vocabulary for physical courage" (pp. 25-26, note 8). It is this additional dimension that anchors the self and provides the basis for it to evaluate all things, even life itself: "Life I desire, duty ( $y i)$ too I desire; if I cannot get to have both, rather than life I choose duty. . . . Therefore there are things one desires more than life and things one hates more than death" (Mencius, 6A/10, cited in Graham, 2002, p. 27). Thus strong evaluation is replete with contrastive terms, right versus wrong, noble versus base, good versus bad. For instance Confucius distinguishes between the right kind of worry (to be concerned about not acknowledging others) 
from the wrong kind of worry (not being acknowledged by others) (Analects, 1/16); and between the wrong kind of shame (due to poor clothing and food, Analects, 4/9) and the right kind of shame (due to failure to live up to one's own words, Analects, 4/22).

To evaluate our desires is to form "second order desires," which is "the power to evaluate our desires, to regard some as desirable and others as undesirable" (Taylor, 1985, p. 16, emphasis in original). According to Frankfurt (1971), while all animals exhibit desires, only humans exhibit the desire to have certain kinds of desires and not others. But the articulation of "second order desires" is hampered when we fail to make explicit the moral map of our preferences. Seligman's model of the good life (2002) is a case in point. Consider the following statements about positive psychology:

It is not the job of positive psychology to tell you that you should be optimistic, or spiritual, or kind or goodhumored; it is rather to describe the consequences of these traits (for example, that being optimistic brings about less depression, better physical health, and higher achievement, at a cost perhaps of less realism). What you do with that information depends on your own values and goals. (p. 129)

Two schemes of evaluation have been offered to asses claims of the good life such as optimism: one scientific and objective, the other seemingly arbitrary and subjective. The latter is a black box- "your own values and goals" whatever that may be; the former has slightly more intelligibility - the cost benefit analysis-but not much. Taylor (1985) refers to the approach that abandons the language of qualitative contrast and evaluates the alternatives purely as a balance of utility a "simple weigher of alternatives" (p. 23). This is a classical example of "weak evaluation" (Taylor, 1985).

The problem with weak evaluation is its lack of articulacy. Weak evaluation is not equipped to articulate the "horizon of intelligibility" that forms the backdrop of our preferences. If one were to choose optimism, Seligman gives us two reasons for this preference: its utility and a truth claim bolstered by empirical evidence. For the lay person, this form of reasoning fosters intellectual laziness-one simply has to go by what the experts say, be they the Pope, the Dalai Lama, or the scientist. This type of reasoning also lacks the reflexive dimensionthe desire of desire or "second order desire" (Taylor, 1985). Weak evaluation is concerned exclusively with the object of desire-the quality of the object gives the basis for one's preference-leaving the quality of desire itself unquestioned. Otherwise put, it lacks "a vocabulary of worth" (Taylor, 1985, p. 24), that is concerned with the "qualitative worth of different desires" (Taylor, 1985, p. 16), i.e., desires can be right or wrong, noble or base, good or bad. It is this contrastive char- 
acterization of desires that gives strong evaluation an edge of advantage over the "simple weigher of alternatives" For instance, one needs the vocabulary of strong evaluation to be able to say that the desire for optimism is wrong when fighting an unjust war. Or that the optimism that "the U.S. will root out all its enemies" (Seligman, 2002, p. 92) is a dangerous illusion. Not having the vocabulary to articulate our evaluation of desires, Seligman retreats to the black box of subjective judgment that supposedly fall outside the pale of science. Likewise, when he places the "meaningful life" at the apex of his three types of happiness, he has no other recourse except to say that it is his own personal preference.

Because of its acute inarticulacy, weak evaluation cannot handle choice between incommensurables that have equal utility and equal truth claims. Consider the dilemma many Confucian sons have faced in the past: "a man has the duty to answer the ruler's call to fight at the front line. What if his aging parents also need his daily assistance?" (Li, 1999, p. 104). Weak evaluation cannot make intelligible the moral dilemma and its resolution, as Taylor (1985) points out: "faced with incommensurables, which is our usual predicament, the simple weigher's experiences of the superiority of A over B are inarticulable" (p. 24). Fortunately or unfortunately, Seligman's model does not have to deal with incommensurables-there are none to be found. The hedonic contrast between positive and negative emotions is not a contrast between incommensurables, as Taylor (1985) points out rightly that "the contrast between pleasure and pain is not a qualitative contrast of desires of desired consummations-only pleasure is desired" (p. xx, emphasis in original). Weak evaluation fails to include in its equation of happiness hard questions - such as moral conflicts or the dilemma of incommensurables - that no meaningful life is ever without. Worse yet, it has the potential to render our experiences of such hard questions inarticulate and flat. To the extent that, as "selfdescribing animals" (Taylor, 1985), our experiences are shaped by the language we use to describe them, "This deflated description is part of the objectifying, calculating way .... to experience the choice, and is 'constitutive' of this experience" (Taylor, 1985, p. 37). Seligman's notion of virtue is a case in point.

In the Confucian context, virtues are prerequisites for being human. As such, they constitute the horizon of significance that makes our choices intelligible. In Seligman's model, virtues become an inventory of "signature strength" As "signature strength," virtues become optional-like the different flavors of ice cream, it's a matter of personal choice. But self choice cannot be the last word, as Taylor points out: "Self-choice as an ideal makes sense only because some issues are more significant than others. . . . Which issues are significant, I do not determine. If I did, no issue would be significant. But then the very 
ideal of self-choosing as a moral ideal would be impossible" (1997, p. 39 , emphases in original). In the final analysis, the weak evaluator is a science fiction, as Charles Taylor points out that "in fact the human beings we are and live with are all strong evaluators" (1985, p. 28). Thus we are led to the next logical question: what are the (implicit) values and preferences of positive psychology? This question is addressed in the next section, where I demonstrate that science can bring to light, rather than render invisible, the horizons of significance behind visions of the good life, East and West.

\section{Visions of the Good Life, East and West}

The most readily identifiable value system behind positive psychology is rational utilitarianism. Characteristic of this value system is its emphasis on what Goldberg (1998) refers to as "mastery at a distance" in the sense that "the space that separates the object world and the rational subject is the space of instrumentality" (pp. 33-34). A case in point is the games of synchrony that Seligman (2002) plays with his children in their first years of life:

Over lunch, after Carly has satisfied her appetite for Cheerios, we wait for her to bang on the table. When she bangs, we all bang. She looks up. She bangs three times; we all bang three times .... Within a minute, we are all enjoying gales of laughter. In addition, Carly is learning that her actions influence the actions of the people she loves - that she matters. (pp. 215-216)

Seligman claims that in these games "The crucial variable is contingency-learning that your actions matter, that they control outcomes that are important" (p. 215, emphasis in original).

Confucius also played games of synchrony-with grownups:

When the Master was in company with a person who was singing, if he sang well, he would make him repeat the song, while he accompanied $[h o]$ it with his own voice. (Analects, 7/31, in Legge, 1971, Vol.1 p. 205).

For Confucius, synchrony has a different connotation. Instead of mastery of the environment, it signifies a sense of affinity between the self and the other. More specifically, the term "ho" means to resonate or harmonize. This term is used to give a primordial imagery of resonance in the "Chung $F u$ " hexagram (61) of I-Ching (Wilhelm, 1950, p. 237):

A crane calling in the shade.

Its young answers $[h o]$ it. 
Here "ho" (resonating) refers to the instinctual response of the young to the call of its mother. Alleged commentary by Confucius on this $I$ Ching passage says it well: "Things that accord in tone vibrate together. Things that have affinity in their inmost natures seek one another. Water flows to what is wet, fire turns to what is dry. . . "(Munakata, 1983, p. 106). Resonance is referred to by Hall and Ames (1987) as "the language of deference," which is a discourse in which "meaning is disclosed and/or created by virtue of a recognition of mutual resonances among instances of communicative activity" (pp. 294-295).

The contrast between the language of mastery and that of deference is consistent with the theories of Individualism versus Collectivism, and independent versus interdependent cultures. However, these prevalent models of culture are derived from a frame of reference more socio-political than psychological. I propose, as complement, a theoretical model that is based on neuro-psychological explanations for the observed cultural differences. This model is an extension of Higgins' theory of self-regulatory systems $(1997,1999)$.

\section{An Extension of Higgins' Model}

Higgins (1999) postulates two different self-regulation systems-one with a promotion-focus, the other with a prevention-focus. The neuropsychological underpinnings of the promotion-focus regulation correspond to, in very general terms, the reward system, which manages incentive motivation and approach; those of the prevention focus system correspond to the fear system, which manages aversive motivation and avoidance (Gray, 1990). The relevance of this theoretical framework to our notion of happiness and the good life has been noted by Carver:

Both approach and avoidance have the potential to induce positive feelings (by doing well); both also have the potential to induce negative feelings (by doing poorly). But doing well at moving toward an incentive is not quite the same as doing well at moving away from a threat. Thus, the two positives may not be quite the same, nor the two negatives quite the same. (2003, p. 244)

An extension of Higgins' model is the deviance regulation theory (Blanton \& Christie, 2003), which translates promotion focus into seeking of desirable deviance; and prevention focus, avoidance of undesirable deviance. As another permutation of the same theme, I transpose the proposed deviance regulation from its original social framework to the context of self to self transaction. This permutation states that in the deviance-avoiding/prevention-focus cultures, the normative self is understood in terms of desirable states such as equilib- 
rium ( $\mathrm{Li}, 1992)$, or an innate nature which is supposed to be good. In the deviance-seeking/promotion-focus cultures, the normative state of the self is understood in terms of undesirable traits such as the original sin or lethargy due to lack of stimulation. Thus in promotion-focus cultures, deviance from the normative state of the self is cast in terms of desirable alternatives such as activation and action, whereas in prevention-focus cultures, deviance from the normative self is cast in terms of undesirable alternatives such as perturbation of being.

Another set of terms to be introduced, and the extension of Higgins is complete: novelty-focus versus authenticity-focus (Sundararajan, 2002a; Averill \& Sundararajan, 2004). This set of terms refers to directions of cognitive attention-outward toward the world versus inward toward the self-cognitive orientations that help to shape the nature and content of our emotional experiences (see Lambie \& Marcel, 2002). Novelty-focus has significant overlap and affinity with deviance seeking, whereas authenticity-focus, the deviance avoiding/norm conserving tendencies. More specifically, novelty-focus has an outward orientation in which the self to world transaction is privileged over the self to self transaction, since the former relative to the latter has more novelty in stock. Conversely, authenticity-focus has an inward orientation in which the self to self transaction is privileged over the self to world transaction, since the authenticity-focused self is preoccupied with the norm conserving task of being true to itself.

Now the stage is set for an application of the extended version of Higgins' theory. The proposed model states, in very general terms and leaving the nuances to be added later, that Seligman's definition of the good life is under-written by the promotion-focus self regulation system; and the Confucian vision of the good life, the prevention-focus system. In the following paragraphs, I substantiate this claim by making a running comparison between Seligman's Authentic Happiness (2002) and classical Confucian texts on three registers: inward versus outward orientation, approaches to emotions, and ideal attachment figures.

\section{Inward versus Outward Orientation}

A good example of the promotion-focus orientation is the following statement of Seligman (2002):

Lying awake at night, you probably ponder, as I have, how to go from plus two to plus seven in your life, not just how to go from minus five to minus three and feel a little less miserable day by day. (p. xi)

As Higgins (1999) points out, from the perspective of promotion-focus self regulation, having accomplished one's life goals might not be enough - "it might be necessary to remain eager for more 'hits" ( $p$. 
263). Contrary to Seligman's prediction, however, going from minus five to minus three in the reduction of misery makes perfect sense from the perspective of the prevention-focus self regulation. Better still, the ultimate goal of the deviance-avoiding/norm-conserving regulation is returning to the original state of being before perturbation. A reigning imagery for this state of being is that of still water. Thus the Taoist text Chuang-tzu states:

It is the nature of water that if unmixed it is limpid, if nothing stirs it is level. ... This is a symbol of our virtue from Heaven. Therefore it is said: to be pure and unmixed, unchanging in stillness and unity, calm and without action ... (Ch. 8, cited in Grahm, 2002, p. 10)

Averill and More (2000) have captured these two different versions of the good life with their distinction between high and low activation as two broad categories of happiness across cultures. In contrast to the emotions of high arousal-such as joy, love, hope-spawned by promotion focus self regulation, Being oriented emotions-such as serenity, inner harmony, and mindfulness-are of low arousal. This is consistent with the observation of Kitayama and Markus (2000) that Japanese, and by extension Chinese, are primed more to arousal than to pleasantness dimension, not to max positivity and minimize negativity, but to keep a good balance between the two so as to stay "calm," "undisturbed," "unaroused" (p. 139).

Consistent with the norm-conserving and deviance-seeking divide, the quiescence orientation tends to turn inward, whereas the action orientation, outward. Consider a ubiquitous item in the self-esteem questionnaires in the West: "when people praise me, my self esteem goes up" Such external benchmarks are curiously missing in the version of self development endorsed by Confucius:I

The Master said, "At fifteen I had my heart bent on learning. At thirty, I stood firm. At forty, I had no doubts. At fifty, I knew the decrees of Heaven. At sixty, my ear was an obedient organ for the reception of truth. At seventy, I could follow what my heart desired, without transgressing what was right. (Analects 2/4, in Legge, 1971, Vol.1, pp. 146-147)

With the exception of being (socially) established ("stood firm") around thirty, the benchmarks of self development for Confucius are completely internal. The ultimate goal is inner freedom, made possible by a hard earned harmony between desire and conscience. This inner freedom is captured by the term "an," which literally means safe, secure, calm, tranquil, and content, and is closely associated with the concept of dwelling - the ideogram consists of a woman under a roof, thus the connotations of protection and safety. Ames and Rosemont's 
(1998) rendition is best: "dwell content" ( p. 78). Characteristic of the authenticity-focus cultures, freedom from perturbation inevitably translates into inner freedom-the good life is to be sought in the harmony within.

Take another example, the discourse on love. In praise of those who have the capacity to love and be loved as a "signature strength," Seligman (2002) writes: "Love flows out of them like a river and they soak it up like sponges, and this is the straightest road to love " (p. 207). In sharp contrast to this outward orientation of love is the self-reflexive version of love in the following reflections on benevolence (ren, or jen) recorded in Hsün Tzu: three disciples of Confucius gave their responses to the question posed by the Master: what is the jen person like? Tzu-lu replied, " one who causes others to love him"; Tzu-kung replied, "one who loves others"; Yen Yüan replied, "a benevolent person is one who loves himself" (adapted from Ames, 1991, p. 106). According to Ames (1991), these three answers reflect three levels of moral understanding: the first level of moral understanding as indicated by the first answer entails "a selfishness"; the second level as indicated by the second answer is higher, "but is self-effacing" Ames concludes: "The highest level, then, is necessarily reflexive" (1991, p.106).

Consistent with the deviance-seeking and norm-conserving divide, novelty-focused cultures privilege the notion of emotion as passion, as transitory responses to external perturbations; whereas authenticityfocus cultures, the notion of emotion as something internal and stable (see Averill \& Sundararajan, 2004). To wit, there is a tendency for the Confucian tradition to turn emotions into virtues/traits. Filial piety, for instance, is by no means a transitory warm and fuzzy feeling toward one's parents - it is the cardinal virtue that takes one a lifetime to live up to. Conversely, it is interesting to note the tendency to turn virtue into emotions in the work of positive psychologists. In one gratitude study by Emmons and McCullough (2002), the researchers asked the gratitude group to keep daily diary for 2 weeks of happenings to be grateful for. Seligman (2002) reports the finding of this study that "joy, happiness, and life satisfaction shot up for the gratitude group" (p. 75). Similarly Seligman (2002) asked students to write and read their testimonial of gratitude to the person they owed their thanks to, with the following instruction: "read your testimonial aloud slowly, with expression, and with eye contact. Then let the other person react unhurriedly. .." (p. 74, emphasis added). There were no dry eyes, he wrote; and students reported of being "on a high" for the next few days.

From the Confucian point of view, it is a travesty to think of virtues - the internal-stable traits-in terms of the externally caused transitory emotional responses. The two differ not only in ontological status, but also in practice-the former is to be cultivated, whereas the 
later transcended. One of the coping mechanisms recommended by Confucius is to look inward in times of adversity to see whether one has done anything wrong to have caused the hardship. "When internal examination discovers nothing wrong, what is there to be anxious about, what is there to fear?" (Analects, 12/4, Legge, 1971, Vol.1, p. 252). And if fear is to be transcended, so is hope. Hope is a passion, a transitory response to environmental perturbations that one does well to transcend. As predicted, the term hope cannot be found in the Analects (see Averill \& Sundararajan, 2004).

How about optimism, surely that is a stable trait? The answer to this question is a qualified yes. The Confucian version of optimism has a different attribution style. Western optimism entails a particular reading of the binary opposition of the external-transitory states versus internal-stable traits, with negative outcomes attributed to the former and positive outcomes to the latter. This polarization of the positive and negative, and this particular bias in attribution are consistent with the promotion-focus, but not applicable to prevention-focus regulations. The key question from a prevention-focus perspective is: which is more preventable, the external-transitory factors, or internal-stable ones? A sensible answer to this question would be to accept the former, since it is not preventable, and invest one's energy instead on what is preventable - the internal stable factors. This is indeed the argument of Hsün Tzu who makes a distinction between intrinsic or just shame versus circumstantial shame (Cua, 1996, p. 196, note 48), and argues that a gentleman may have circumstantial shame, but not intrinsic shame, for "the former is a matter of circumstance beyond one's power or control, while the latter has a source within oneself" (Cua, 1996, p. 183).

\section{Different Approaches to Emotions}

Positive psychology seems to fit the profile of a type of emotion regulation strategy referred to by Labouvie-Vief (2003) as optimization. She reports findings that individuals who emphasized hedonic tone (high positive affect but low negative affect) had "high ratings on selfacceptance, a sense of mastery, and purpose in life" (p. 204). Consistent with the optimization strategy to polarize emotions, Seligman (2002) gives a long litany of why negative emotions are bad for you. Also characteristic of the optimization strategy is the tendency to use positive emotions to undo or buffer against negative ones, especially hopelessness and depression (p. xiv). A very different approach to emotions is found in the Analects.

The ubiquity of hedonic pairs in the Analects — such as like-dislike $(4 / 3,15 / 27,4 / 6,13 / 24)$, love-hate $(12 / 10)$, joy-displeasure $(5 / 18)$, joyanxiety (4/21), enjoyment-sadness ( $3 / 20)$ - suggests an impartiality toward positive and negative emotions, a balanced perspective fos- 
tered by the philosophy of complementarity as best embodied by the yin-yang symbol (Peng \& Nisbett, 1999). At a closer look, however, there is an unmistakable tendency toward "hypercognization" (Levy, 1973) — as evidenced by finer differentiation — of negative emotions. A case in point is the nuanced and complex approach of Confucius toward the sadness cluster as evidenced by the Analects (Legge's edition, 1971, Vol.1). Although chronic sorrow/distress is considered an attribute of the "petty" men (7/36), sadness in the context of the mourning rites is fundamental, without which one lacks the basic qualities of being human (3/26). Confucius believes in moderation: sadness should not be in excess (3/20). But when the occasion calls for it, excess mourning is the right thing to do (11/9). He also privileges the intensity of deep sorrow in mourning (3/4).

Even more central than sadness is fear. Consistent with the prevention-focus hypothesis, fear and anxiety form the largest cluster in the Analects (Legge's edition, 1971, Vol.1). Some simple statistics: the worry and anxiety cluster consists of 3 terms-you, huan, bing-that are mentioned in 20 chapters; fear is a highly differentiated concept, consisting of a cluster of 7 terms-ju, jing, wei, dan, li, xi, kong-that are mentioned in 15 chapters of the Analects. Together, fear and anxiety appear in 35 out of a total of 499 chapters of the Legge's edition, a frequency leaving in the dust the next largest cluster, which is happiness consisting of only 4 terms -yue, le, $x i, y u$-and indexed in 26 chapters. Happiness seemed to serve as a buffer of-not unhappiness, but anxiety. Confucius said of himself that he enjoyed himself so much that he forgot to worry (7/18).

Other negative emotions that play important roles in the Confucian morality are commiseration, shame and dislike/aversion. In the philosophy of Meucius, these negative emotions become the foundations of virtue:

The feelings of commiseration belongs to all men; so does that of shame and dislike; and that of reverence and respect; and that of approving and disapproving. The feeling of commiseration implies the principle of benevolence; that of shame and dislike, the principle of righteousness; that of reverence and respect, the principle of propriety; and that of approving and disapproving, the principle of knowledge [wisdom]" (Mencius, 6B/6, Legge, 1971, Vol. 2, p. 402, emphasis in original)

One of the negative emotions that is made pivotal to the Confucian definition of being human is commiseration. Although neither its root metaphor of sympathy nor its possible neurological connection with the "mirror neurons" (Gallese, 2001) is necessarily negative hedonically, the Chinese version of sympathy has a distinctively negative spin 
as "commiseration," or "sympathy for misfortune," or more literally as "grieving-pity-of-mind" The following pronouncement of Mencius on this topic is canonical:

Now, when men suddenly see a child about to fall into a well, they all have a feeling of alarm and distress, not to gain friendship with the child's parents, nor to seek the praise of their neighbors and friends, nor because they dislike the reputation [of lack of humanity if they did not rescue the child]. From such a case, we see that a man without the feeling of commiseration is not a man. . . . The feeling of commiseration is the beginning of humanity. (Chan, 1963, p. 65)

Richards explains: "The suggestion in 'grieving-pity-of-mind' of a shuddering qualm is strong. ... The 'noise' is the unpleasant sound of the child thudding down into the well, not the mere rumor or report of what has happened" (1964, p. 19).

This hedonically negative spin on sympathy makes sense, from the perspective of prevention-focus regulation, especially if it is cast in the interpersonal context. To the extent that the ideal state for the prevention-focus regulation is freedom from perturbation, or "an" (dwelling content, or feeling at ease), effective prevention would require lowered threshold for perturbation. In the interpersonal context, to the extent that one is committed to the protection of the other's ease ("an"), it is imperative for the self to develop a high threshold for one's own ease, or conversely a low threshold for perturbation by the other's suffering. This "negative capability" is referred to as the "unbearing mind""the mind which cannot bear to see the sufferings of others" (Bloom, 2002, p. 75). The high threshold for "an" as the hallmark of virtue is the theme of the following scenario from the Analects (17/21):

Zaiwo asked about the three years' mourning for parents, saying that one year was long enough. The Master said, 'if you were, after a year, to eat good rice, and wear embroidered clothes, would you feel at ease [an]?" "I should," replied Wo.

The Master said, "If you can feel at ease, do it. But a superior man, during the whole period of mourning, does not enjoy pleasant food which he may eat, nor derive pleasure from music which he may hear. He also does not feel at ease, if he is comfortably lodged. Therefore he does not do what you propose. ... (Legge, 1971, Vol. 1, p. 328 , emphasis in original)

The hedonically negative connotation of sympathy may also be understood in terms of intersubjective vulnerability - the capacity to 
suffer for the other. When one of his favorite disciples Yen Hui died, Confucius mourned for him:

The disciples noticed that the wailing of Confucius went beyond the limits of ritual decorum (just as the recluse noticed that his chime beating was improperly impetuous). "Master," they said, "You are afflicted," to which he replied, "Am I afflicted? If I am not to be afflicted for this man, for whom am I to be afflicted? (Analects, 11/9, cited in Henry, 1987, p. 23, emphasis added)

In the above scenario, the subjectivity of Confucius was shot through and through by an Other: the crucial question for Confucius was not whether he was having positive or negative emotions, but rather "for whom" was he having his passions/afflictions. Confucius was not alone in his understanding of emotions as primarily a matter of "for whom" "I have no regrets as my girdle grows too spacious for my waist; with everlasting love for you I pine" (Tu, 1977, emphasis added). These lines by the poet Liu Yung (990?-1050?) say the same thing. Shaver et al. have made the astute observation that "sad aspects of love and attachment are hypercognized in China (i.e., are frequently noticed, emphasized, thought about, and articulated)" (Shaver, Wu, \& Schwartz, 1992, p. 196). A case in point is the "heart aching love" (xin teng) rendered "sorrow/love" by Shaver et al., who found that $70 \%$ of the Chinese mothers of 30- to 35-month-olds claimed that their children could understand this term (p. 199). This is not surprising, given the fact that the English equivalent of this term is something like "doting" Thus children are often teased with the question, "does your mother's heart ache for you?" It is also common for mothers to say "my heart aches" in reference to the plight of their children. Unmistakable in this common household expression of love is the ethos of intersubjective vulnerability, an ethos that measures love and attachment primarily in terms of the extent to which one is willing to be afflicted by the Other, and for the Other. In light of this intersubjective vulnerability, it can be surmised that the expressions of negative, rather than positive, emotions are pro-social, as they give the other person the opportunity to exercise the capacity for sympathy. This is consistent with the observation of Kitayama and Markus that self criticism is necessary for participating in mutually sympathetic social relations (2000).

\section{Ideal Attachment Figures}

Corollary of the good life is the good person. The ideal person from the perspective of the prevention-focus system is one who embodies the security-related regulation-one who is concerned with security, safety and responsibility (Higgins, 1999). In contrast, the ideal person from the perspective of the promotion focus system is one who shows 
warmth and affection, and inspires with reward and incentives. For instance, when the caretaker "hugs and kisses the child for behaving in a desired manner" (Higgins, 1999, p. 246). This difference in care taking corresponds to two types of attachment systems-attachment and affection, which are generally subsumed under one attachment theory, but warrant finer differentiation by emotion theorists (Oatley, 2000).

In his treatment of the attachment phenomena, Panksepp (1998) made an important distinction between attachment to nests versus that to the caretaker, by pointing out how rat pups feel secure at nest sites even without the mother in it (p. 248). That the components of attachment need to be parsed further is suggested by MacDonald (1992), who argues that "the systems underlying warmth and intimacy in human relationships must be distinguished from the systems underlying the propensity for fear in the absence of an attachment object" (p. 754). In support of this distinction, Fox and Davidson (1987) have shown that on the approach of their mother with open arms, infants showed joy and activation of the left side of the cortex, whereas with the approach of a stranger, fear and activation of the right side of the cortex.

Possible dissociation between the reward system that under-girds warmth and affection and the fear system that under-girds security of attachment is also supported by data from other cultures that show securely attached infants being cared for by mothers who showed sensitivity and responsivity, but without demonstrativeness of warmth and affection, as reported by Ainsworth's Uganda study (1967). Similarly, LeVine and LeVine (1966) reported that among the Gusii of Kenya: "It is rare to see a mother kissing, cuddling, hugging, or cooing at her child" (p. 126), and that mothers nursed their infants "mechanically, without looking at the child or fondling him" (p. 122).

The distinction between the two types of attachment-the primordial attachment to the nest site versus warmth and affection toward the caretaker - seems to fall along the divide between low and high activation in cultural narratives of the good life (Averill \& More, 2000), as well as that between prevention- and promotion-focus regulation systems. Consistent with the quiescence oriented, prevention-focus regulation is the classic definition of the attachment figure by Bowlby and Ainsworth "as a person whom the child uses as a secure base across time and situations" (Posada et al., 1995, p. 27). This quiescent state, as denoted by the Chinese term "an", seems to be the corollary of attachment to nest site in animals. And the Chinese notion of being one with Nature or the Tao seems also to stem from this primordial, depersonalized, or transpersonal sense of connectedness.

In contrast to the calming effect of the caretaker who functions as the secure base, the attachment figure that embodies the warm/affection system is arousing. Schore (1994) notes the child's elation at see- 
ing mother's face, and the "rewarding and exciting" properties of the mother's gaze, which results in activation of "reward circuit" (p. 83) of the child, rather than a quiescent state. A good example of what Schore (1994) refers to as the child's "modulated increased levels of stimulation" (p. 85) by the mother is found in Stern's description of the interaction between mother and child:

Joy is the product of a mutual regulation of social exchange by both partners. Smiling back and forth is the prototypic example; it usually begins at a relatively low level of intensity. Each partner then progressively escalates-kicking the other into higher orbit . . . The exchange occurs in overlapping waves .... until, most often, simultaneous mutual hilarity breaks forth. (Stern, 1990, p. 16)

Consistent with this promotion-focus perspective, the ideal caretaker in the West is one who activates the reward system in a manner expected of God, the ultimate attachment figure, in St. Augustine's plea: "Up, Lord, and do; stir us up, and recall us; kindle and draw us; inflame, grow sweet unto us; let us now love, let us run" (Pusey, 1949, p.151). A more mundane version of the ideal caretaker is found in the "Best Moments" method at bedtime recommended by Seligman: the typical scenario (Seligman, 2002, pp. 226-228) starts with "What did you like doing today, Lara-love?" And ends with the child (Lara) saying, "Wow, fifteen good things in one day! What are we gonna do tomorrow?" The caretaker in this ritual embodies the promotion focus regulation strategies-being demonstrative of affections and inspiring hope and optimism by helping the child to recount positive things she has done during the course of a day. The arousing nature of this ritual is borne out by Seligman's own experience that it worked well with children after five-with younger children, "they got so excited about the next day that they couldn't sleep" (p. 227). The prevention-focus care taking strategies, in contrast, are more geared toward having a calming effect.

Consistent with the prevention-focus perspective, the ideal caretaker in the Chinese tradition is committed to the goals of safety and protection, a commitment that finds an eloquent expression in the aspirations of Confucius (Analects, 5/25):

The Master said, "I would like to bring peace and contentment to the aged, to share relationships of trust and confidence with my friends, and to love and protect the young" (Ames, \& Rosemont, 1998, p. 102).

The commitment to protection and the vigilance that goes along with it help to explain why worry tends to loom large in the attachment narratives of the Chinese: Meng Wubo asked about filial piety. The Master 
said, "Parents are anxious lest their children should be sick" (Analects, 2/6, Legge, 1971, Vol. 1, p. 148). According to another rendition of the text, the Master replied, "Give your mother and father nothing to worry about beyond your physical well-being" (Ames \& Rosemont, 1998, p. 77). Either version bespeaks of the anxiety prone caretaker. This is another instance of the lowered threshold for perturbation as a hallmark of virtue - the good caretaker is one who has the sympathetic sensitivity or intersubjective vulnerability to detect stress in others and thereby provides timely relief. Consistent with this observation is the finding of Rothbaum, et al. (2000) that Japanese parents prefer to anticipate their infants' needs, and take anticipatory measures to minimize the stress. This scenario may be mistaken for "insecurely attached" parenting in the attachment literature. Indeed, Rothbaum et al. point out how descriptions of "mothers of insecurely attached babies" in the West would apply to most Japanese mothers' painstaking efforts at making themselves available to the young children.

\section{Concluding Discussions}

More than its empirical investigations, a potentially significant contribution of positive psychology lies in its strong version, the claim to articulate a scientific vision of the good life. This bold claim challenges psychology to close the existing gap between science and life (Bourdieu, 1977; Sundararajan, 2002b). As an attempt to capitalize on this path-breaking potential of positive psychology, this paper examines the problems inherent in a scientific version of the good life. The foregoing analysis culminates in a critique that centers around issues concerning science and value. Seligman's approach to the science and value question is riddled with contradictions. On the one hand, his neutrality claim upholds the science and value dichotomy; on the other, his project of empirically based version of the good life conflates "is" and "ought" (Gergen, 2003). Further compounding the issues is the assumption that value (the good life) depends on science for its validation, when in fact science itself is shaped by value (Slife, 2003). At a philosophical level, these contradictions are part and parcel of the problems that plague naturalism. Since naturalism has been addressed by other writers (Griffith, 2000; Richards \& Bergin, 1997; Slife, 2003), I will focus instead on a more concrete level the three problems inherent in positive psychology's vision of the good life, and their potential remedies.

\section{Marketing the Good Life as Generic Wine}

"And this is the happy life, to rejoice to Thee, of Thee, for Thee " (Saint Augustine, translated by Pusey, 1949, p. 218). A good life has nuances and dimensionality. In the above statement of St. Augustine, each preposition indexes a possible dimension of the emotional life, of 
which only the dimension of "for thee" in the context of sympathy has been addressed briefly in this paper. To do justice to the richness and complexity of the good life, psychology needs not an inventory of traits so much as a fine grained cultural description.

Empirical validation is akin to performing chemical testing on the wines of the good life. According to one report in Science News (Christensen, 2000), chemical testing can identify "the common characters of wines, so that reliable and palatable wines-the Cokes of the wine world — can be made and marketed at a reasonable price" (p. 12). But mass production of generic wine has not been the aspiration of the technology. Quite on the contrary, "now, science is ... asking whether chemical analyses can help authenticate where a wine was made and pin down the elusive nature of terroir" (p. 12 ), which refers to "a vineyard's particular combination of soil, rock, and geography" (p. 12). If the particular is what's important about good wines, how much more so the good life? While the science of well-being (see Kahneman, Diener, \& Schwarz, 1999) follows basically the generic approach that addresses happiness at the national, and societal level, its direct translation into a recipe of the good life is tantamount to the marketing of generic wines. A fine grained cultural description that brings to light the dazzling variety of the good life remains an exciting possibility yet to be explored in positive psychology.

\section{A Culturally Encapsulated Approach to the Good Life}

The culturally encapsulated nature of positive psychology has been documented by the cross cultural analysis in this paper, and by others (Sawyer, 2002; Kitayama \& Markus, 2000). In this section, I explore its methodological ramifications by comparing the different approaches to virtue, East and West.

Seligman's approach to virtue as "signature strength" is consistent with the deviance regulation theory (Blanton \& Christie, 2003), which states that in deviance-seeking societies, socially desirable actions are desired but not required, giving rise to "optional ideals," which are "positive distinctions people can choose to pursue or choose not to pursue, depending on their ability and interest levels" (p. 129). Consistent with this perspective on virtues as "optional ideals" is Kupperman's (2002) claim that the contemporary Anglo-American ethical philosophy is preoccupied with "big moment ethics," which focuses on "major choices at ethical crossroads" (p. 40), leaving "almost all of life apart from the big moments as an ethical free-play zone, in which one can do whatever one likes" (p.40).

In sharp contrast is the whole cloth approach to virtue spawned by the norm-conserving regulatory system (Blanton \& Christie, 2003). In societies where socially desirable actions are desired and required, where everyday ethics, instead of "big moment ethics" reigns, there is 
the "tendency to think of a good life as a seamless web" (Kupperman, 2002 , p. 42). In this cultural context, where certain socially desirable actions are expected of all, what is informative is not what-the presence or absence of a trait or skill, but how. How are the skills applied in various contexts, and how do the traits fit together into a personal style - to have a good life is tantamount to becoming a certain sort of person, with a certain personal style. Kupperman (2002) points out that Western philosophy in general has shared Aristotle's relative inattention to "the role of nuances of style in personal connections, and has largely failed to explore the ways in which personal style, connectedness with others, and virtues add up to a life worth living on a minute-to-minute basis" (p. 41). This vacuum is filled by the Analects which is replete with nuanced accounts of personal styles. "The Master was mild, and yet dignified; majestic, and yet not fierce; respectful, and yet easy" (7/37, Legge, 1971, Vol. 1, p. 207). Or consider a longer account of the Master (10/5):

When he was carrying the scepter of his ruler, he seemed to bend his body, as if he were not able to bear its weight. He did not hold it higher than the position of the hands in making a bow, nor lower than their position in giving anything to another. His countenance seemed to change, and look apprehensive, and he dragged his feet along as if they were held by something to the ground. In presenting the presents with which he was charged, he wore a placid appearance. At his private audience, he looked highly pleased. (Legge, 1971, Vol. 1, pp. 229-230, italics in the original translation)

From the perspective of the whole person, it is meaningless to talk about acquisition of traits without taking into consideration the kind of person who possesses them. Surely between a happy Nazi and a happy Dalai Lama there spans a world of difference. Thus the Master said, "It is only the (truly) virtuous man, who can love, or who can hate, others" (Analects, 4/3, Legge, 1971, Vol. 1, p. 166). The stark contrast between the two approaches to virtue, espoused by the heirs of Aristotle and Confucius respectively, gives support to the growing awareness of the need in psychology for a paradigm shift (Smith, Harre, \& Van Langenhove, 1995; Marsella, 1998) from the study of universals to that of complex interacting particulars; from making inventory of traits to an in depth study of what anthropologists call "practice" (Bourdieu, 1977), which takes into consideration the application of skills in contexts. Will positive psychology meet this challenge? Only time will tell. 


\section{Good Life Sans the Moral Map}

The empirically validated vision of the good life is a happiness donut with something missing at its very core-the moral map. And along with the moral map, the ability to evaluate moral claims. Seligman sees in empirical evidence a better alternative than authority (the Bible, Confucius, etc.) as possible groundings for our values. But to the lay person, who is not in a position to evaluate the empirical findings of the experts, the authority of science can be as inhibiting to critical thinking as the Latin Bible in Medieval times. Indeed, moral maps are more transparent, when people talk about God and values, terms which are obviously subjective hence open to question. It is when values are bolstered by scientific facts that they become opaque and impervious to critical reflections. In this respect, positive psychology has much to learn from the more successful endeavors in humanistic psychology, where the value question is clearly articulated (see Maslow, 1971; and more recently, Schneider, 2004).

How do we put the moral map back in the picture for positive psychology? The truth of the matter is that the moral map has always been there, except that it has been rendered invisible by the neutrality claim of the scientist. I have demonstrated in the foregoing analysis how psychological theories can render our moral maps visible and transparent by shedding light on the "background of intelligibility" behind our values and commitments. To restore to the moral map its proper place in the scientific vision of a good life, psychology needs to develop, in addition to its empirical prowess, two intellectual capacities: self-reflexivity, and critical thinking.

a. Toward a reflexive psychology: Reflexive psychology is a continuation of the development inaugurated by Saint Augustine, who saw the road to God (read "Truth") as "passing through our own reflexive awareness of ourselves" (Taylor, 1997, p. 27). This means, in practical terms, that the scientist gains through his or her research not only a transcendent foothold toward data "out there," but also some insight into the cultural and historical contexts of his or her own research. In this respect, Seligman's understanding of Escher, the master of selfreflexivity, is incomplete. The following poem by Marvin Levine is cited by Seligman at the front page of his book, Authentic happiness (2002). The poem begins with "Escher got it right./Men step down and yet rise up,/the hand is drawn by the hand it draws,/and a woman is poised/on her very own shoulders" And it ends with "And while whales feeding on mackerel/ are confined forever in the sea,/we climb the waves,/ look down from clouds" Transcendence is only half of the story about self-reflexivity, the Chinese poet Wang Kuo-wei (18771927) would argue. Here is Wang's version of self-reflexivity. Wang's poem, composed to the tune of "Sand of Silk-washing Stream," started out with a similar trajectory of transcendence: "A mountain temple 
dim and far away, its back against the/setting sun-/No birds can reach that height far in the shade,/From above, at the single note of its chime, clouds pause in their/passing" (Liu \& Lo, 1975, p. 508). However, at the climax of transcendence, when the poet tried to "climb the peak, to peer at the bright moon," he took a dramatic self-reflexive turn:

By chance I obtain the Eye of Heaven to look at the world of

Red Dust-

Alas, among the denizens of that sub-lunar region,

Myself is what I see. (adapted from Liu \& Lo, 1975, p. 508)

b. A moral vision beyond weak evaluation: Science needs not be doomed to weak evaluations such as the wishy-washy utilitarianism (Guignon, 2002). A clear and well articulated moral stance can be adopted by science if it is coupled with an equally well developed capacity to evaluate its moral vision in more sophisticated terms than empirical evidence.

One obvious but neglected basis for the evaluation of our moral maps is reason, which according to Taylor (1997) entails the possibility "that you can argue in reason about ideals and about the conformity of practices to these ideals," and "that these arguments can make a difference" (p. 23). From this perspective, the potential danger of moral maps lies not in the strength of their concoction so much as their stagnation due to lack of critical reflection. Thus Taylor (1997) argues for the importance of always calling into question existing visions of the good life, thereby reminding ourselves that the moral maps we draw have room always for change and growth as life itself. Similarly, Rorty warns against the "freezing-over of culture," when "some given vocabulary, some way in which people might come to think of themselves" becomes normative (1979, p. 377). So far as the stagnation of our vision is concerned, there is reason to be vigilant about the popularization of science. Psychology has in the past contributed an arsenal of vocabularies such as IQ, self esteem, etc. that clog the artery of the modern imagination, causing an inflation of these terms as measures of the good life. Might it not follow suit the newly minted "happiness" coin of positive psychology?

*An earlier draft of this paper was presented at the American Psychological Association Annual Convention, 2004, Hawaii. *An earlier draft of this paper was presented at the American Psychological Association Annual Convention, 2004, Hawaii.

\section{References}

Ainsworth, M. D. S. (1967). Infancy in Uganda. Baltimore: Johns Hopkins University Press. 
Ames, R. T. (1991). Reflections on the Confucian self: A response to Fingarette. In M.I. Bockover (Ed.), Rules, rituals, and responsibility (pp.103-114). La Salle, IL: Open Court.

Ames, R. T. \& Rosemont, H. Jr. (1998). The Analects of Confucius/A philosophical translation. New York: Ballantine.

Averill, J. R. \& More, T. A. (2000). Happiness. In M. Lewis \& J. M. Haviland (Eds.),Handbook of emotions (2nd ed., pp. 663-676). New York: Guilford.

Averill, J. R., \& Sundararajan, L. (2004). Hope as rhetoric: Cultural narratives of wishing and coping. In J. Eliott (Ed.), Interdisciplinary perspectives on hope (pp. 127-159). New York: Nova Science.

Blanton, H. \& Christie, C. (2003). Deviance regulation: A theory of action and identity. Review of General Psychology, 7 (2), 115-149.

Bloom, I. T. (2002). Mengzian arguments on human nature (ren xing). In X. S. Liu \& P. J. Ivanhoe (Eds.), Essays on the moral philosophy of Mengzi (PP. 64-100). Indianapolis: Hackett.

Bourdieu, P. (1977). Outline of a theory of practice (R. Nice, Trans.). Cambridge: Cambridge University.

Carver, C. S. (2003). Pleasure as a sign you can attend to something else: Placing positive feelings within a general model of affect. Cognition and Emotion, 17 (2), 241-261.

Chan, W-T. (1963). A source book in Chinese Philosophy. Princeton, NJ: Princeton University.

Christensen, D. (Jan. 1, 2000). The world of wine. Science News, Vol. 157 (1), 12-13.

Cua, A. S. (1996). A Confucian perspective on self-deception. In R. T. Ames, \& W. Dissanayake (Eds.), Self and desception/A crosscultural philosophical enquiry (pp. 177-199). Albany, NY: State University of New York.

Emmons, R., \& McCullough, M. (2002). Counting blessings versus burdens: An experimental investigation of gratitude and subjective well-being in daily life. (Unpublished)

Fox, N., Davidson, R. A. (1987). Electro-encephalogram asymmetry in response to the approach of a stranger and maternal separation in 10-month-old infants. Developmental Psychology, 23, 233-240.

Frankfurt, H. (1971). Freedom of the will and the concept of a person. Journal of Philosophy, 67 (1), 5-20.

Gallese, V. (2001). The 'shared manifold' hypothesis/From mirror neurons to empathy. In E. Thompson (Ed.), Between ourselves/ Second-person issues in the study of consciousness (pp. 33-50). New York: Imprint Academic.

Gergen, K. (2003). Positive psychology: Sampling the vintage, review of Life Goals 
and well-being: Towards a positive psychology of human striving, by $\mathrm{P}$. Schmuck \& K. M. Sheldon (Eds.). Contemporary Psychology, 48 (6), 860-861.

Goldberg, S. J. (1998). Figures of identity/Topoi and the gendered subject in Chinese art. In R. T. Ames, T. P. Kasulis, \& W. Dissanayake (Eds.), Self as image in

Asian theory and practice (pp. 33-58). Albany, NY: State University of New York.

Graham, A. C. (2002). The background of the Mencian theory of human nature. In X.S. Liu \& P. J. Ivanhoe (Eds.), Essays on the moral philosophy of Mengzi (PP. 1-63). Indianapolis: Hackett.

Gray, J. A. (1990). Brain systems that mediate both emotion and cognition. Cognition and Emotion, 4 (3), 269-288.

Griffith, D. R. (2000). Religion and scientific naturalism: overcoming the conflicts. Albany: State University of New York Press.

Guignon, C. (2002). Hermeneutics, authenticity, and the aims of psychology. Journal of Theoretical and Philosophical Psychology, 22 (2), 83-102.

Hall, D. L., \& Ames, R. T. (1987). Thinking through Confucius. Albany, NY: State University of New York.

Heine, S. H., Lehman, D. R., Markus, H. R., \& Kitayama, S. (1999). Is there a universal need for positive self-regard? Psychological Review, 106, 766-794.

Henry, E. (1987). The motif of recognition in early China. Harvard Journal of Asiatic Studies, 47 (1), 5-30.

Higgins, E. T. (1997). Beyond pleasure and pain. American Psychologist, 52 (12), 1280-1300.

Higgins, E. T., Grant, H., \& Shah, J. (1999). Self-Regulation and the quality of life: Emotional and non-emotional life experiences. In D. Kahneman, E. Diener, \& N. Schwarz (Eds.), Well-Being: The foundations of hedonic psychology (PP. 244-266). New York: Russell Sage Foundation

Kahneman, D., Diener, E., \& Schwarz, N. (Eds.). (1999). Well-Being: The foundations of hedonic psychology. New York: Russell Sage Foundation.

Kitayama, S., \& Markus, H. R. (2000). The pursuit of happiness and the realization of sympathy: Cultural patterns of self, social relations, and well-being. In E. Diener, \& E. M. Suh (Eds.), Culture and subjective well-being (PP.113-161). Cambridge, MA: MIT press.

Kupperman, J. J. (2002). Naturalness revisited: Why Western philosophers should study Confucius. In B. W. Van Norden (Ed.), Confucius and the Analects (PP. 39-52). Oxford: Oxford University Press. 
Labouvie-Vief, G. (2003). Dynamic integration: Affect, cognition, and the self in adulthood. Current Directions in Psychological Science, 12, 201-206.

Lambie, J. A., \& Marcel, A. J. (2002). Consciousness and the varieties of emotion

experience: A theoretical framework. Psychological Review, 109(2), 219-259.

Legge, J. (1971). The Chinese classics, Vols. 1 \& 2. Taipei: Wen Shi Zhe Ch'uban Shè. (First edition Shanghai, 1935)

LeVine, R. A., \& LeVine, S. E. (1966). Nyansongo: A Gusii community in Kenya. New York: Wiley.

Levy, R. I. (1973). Tahitians: Mind and experience in the society islands. Chicago: University of Chicago Press.

Li, C. (1999). The Tao encounters the West. Albany: State University of New York Press.

Li, Y. Y. (1992). In search of equilibrium and harmony: On the basic value orientation of traditional Chinese peasants. In C. Nakane \& C. Chiao (Eds), Home bound: Studies in East Asian society (PP. 127-148). Hong Kong: The Center for East Asian Cultural Studies.

Liu, X. (2002). Mengzian internalism. In X. Liu \& P. J. Ivanhoe (Eds.), Essays on the moral philosophy of Mengzi. Indianapolis: Hackett.

Liu, W-C., \& Lo, I. Y. (Eds.). (1975). Sunflower splendor/Three thousand years of Chinese poetry. Garden City, NY: Anchor.

MacDonald K. (1992). Warmth as a developmental construct: An evolutionary analysis.Child Development, 63, 753-773.

Marsella, A. J. (1998). Toward a "Global-Community Psychology": Meeting the needs of a changing world. American Psychologist, 53, 1282-1291.

Maslow, A. H. (1971). The farther reaches of human nature. New York: Viking Press.

Munakata, K. (1983). Concepts of lei and kan-lei in early Chinese art theory. In S. Bush, \& C. Murck (Eds.),Theories of the arts in China (pp. 105-131). Princeton, NJ: Princeton University.

Oatley, K. (2000). The sentiments and beliefs of distributed cognition. In N. Frijda, A. Manstead, \& S. Bem (Eds.), Emotion and beliefs (pp. 78-107). Cambridge: Cambridge University press.

Panksepp, J. (1998). Affective neuroscience. Oxford: Oxford University Press.

Peng, K., \& Nisbett, R. E. (1999). Culture, dialectics, and reasoning about contradiction. American Psychologist, 54, 741-754.

Posada, G., Gao, Y., Wu, F., Posada, R., Tascon, M., Schoelmerich, A., Sagi, A., Kondo-Ikemura, K., Haaland, W., \& Synnevaag, B. (1995). The secure-base phenomenon across cultures: Children's 
behavior, mothers' references, and experts' concepts. Monographs of the Society for Research in Child Development, 60 (2-3, serial No. 244), 27-48.

Pusey, E. B. (Trans.) (1949). The confessions of Saint Augustine. New York: Random House.

Richards, I. A. (1964). Mencius on the mind: Experiments in multiple definition. London: Routledge \& Kegan Paul.

Richards, P. S., \& Bergin, A. E. (1997). A spiritual strategy for counseling and psychotherapy. Washington, DC: American Psychological Association.

Rorty, R. (1979). Philosophy and the mirror of nature. Princeton, NJ: Princeton University Press.

Rothbaum, F., Weisz, J., Pott, M., Miyake, K., Morelli, G. (2000). Attachment and

culture/Security in the United States and Japan. American Psychologist, 55 (10), 1093-1104.

Sawyer, R. K. (2002). Toward a positive psychology, review of Optimism and pessimism: Implications for theory, research, and practice by E. C. Chang (Ed.). Contemporary Psychology, 47 (6), 691693.

Schneider, K.J. (2004). Rediscovery of awe: Splendor, mystery, and the fluid center of life. St. Paul, MN: Paragon House.

Schore, A. N. (1994). Affect regulation and the origin of the self. Hillsdale, NJ: Lawrence Erlbaum.

Seligman, M. E. P. (2002) Authentic happiness/Using the new positive psychology to realize your potential for lasting fulfillment. New York: Free Press.

Seligman, M. E. P., \& Csikszentmihalyi, M. (2000). Positive psychology/An introduction. American Psychologist, 55 (1), 5-14.

Shaver, P. R., Wu, S., Schwartz, J. C. (1992). Cross-Cultural similarities and differences in emotion and its representation/A prototype approach. In M.S. Clark (Ed.), Review of personality and social psychology (Vol. 13), Emotion (pp. 175-212). Beverly Hills, LA: Sage.

Slife, B. D. (2003). Theoretical challenges to therapy practice and research: The constraint of naturalism. In M. Lambert (Ed.), Bergin and Garfield's handbook of psychotherapy and behavior change (pp. 44-83, 5th ed.). New York: Wiley.

Smith, J. A., Harre, R., \& Van Langenhove, L. (1995). Rethinking psychology. London: Sage.

Solomon, R. C., \& Stone, L. D. (2002). On "positive" and "negative"emotions. Journal for the Theory of Social Behavior, 32 (4), 417-435. 
Stern, D. N. (1985). The interpersonal world of the infant: A view from psychoanalysis and developmental psychology. New York: Basic Books.

Sundararajan, L. (2002a). The veil and veracity of passion in Chinese poetics. Consciousness \& emotion, 3 (2), 231-262.

Sundararajan, L. (2002b). An embodied perspective on psychotherapy. Journal of Humanistic Psychology, 42 (2), 34-47.

Taylor, C. (1985). Human agency and language. Cambridge: Cambridge University.

Taylor, C. (1997). The ethics of authenticity. Cambridge: Harvard University.

Tu, C-I. (1977). (Tr.). Poetic remarks in the human world (Jen chien tz'u hua by Wang Kuo-wei). Taipei: Chung Hwa.

Wilhelm, R. (Tr.). (1950). The I Ching (C. F. Baynes, Trans.). Princeton, NJ: Princeton University. 